Article

\title{
Phase Transformation and Dissolution Behavior of Pyrite in the Roasting-Sulfuric Acid Leaching Process of Vanadium-Bearing Stone Coal
}

\author{
Xingjie Wang ${ }^{1,2,3,4, *}$, Yimin Zhang ${ }^{1,3,4, *}$, Tao Liu ${ }^{1,3,4}$ and Yizhong Yuan ${ }^{1,3,4}$ \\ 1 School of Resource and Environmental Engineering, Wuhan University of Science and Technology, \\ Wuhan 430081, China; tkliutao@126.com (T.L.); yyz2039@163.com (Y.Y.) \\ 2 State Key Laboratory of Mineral Processing, Beijing General Research Institute of Mining and Metallurgy, \\ Beijing 102628, China \\ 3 State Environmental Protection Key Laboratory of Mineral Metallurgical Resources Utilization and Pollution \\ Control, Wuhan University of Science and Technology, Wuhan 430081, China \\ 4 Hubei Provincial Engineering Technology Research Center of High Efficient Cleaning Utilization for Shale \\ Vanadium Resource, Wuhan University of Science and Technology, Wuhan 430081, China \\ * Correspondence: wangxingjie@csu.edu.cn (X.W.); zym126135@126.com (Y.Z.)
}

Received: 2 May 2020; Accepted: 4 June 2020; Published: 9 June 2020

check for updates

\begin{abstract}
The selective leaching of vanadium and iron has been one of the main concerns in the field of vanadium recovery from stone coal, but the source of iron ions and their release characteristics were still unclear. In this work, the dissolution of pyrite and its roasted product, under conditions in accordance with the vanadium leaching process from stone coal by blank roasting-acid leaching, were studied. The results indicated that the leaching performances of $\mathrm{V}$ and $\mathrm{Fe}$ in stone coal were significantly correlated, with both depending on the leaching parameters of the $\mathrm{H}_{2} \mathrm{SO}_{4}$ concentration, the leaching temperature, the leaching time and the solid to liquid ratio. Under air conditions, with a roasting temperature of $700{ }^{\circ} \mathrm{C}$, the roasted product of pyrite was hematite. Approximately $45 \%$ of the roasted product dissolved at its optimal leaching condition-35\% higher than that of the raw pyrite. However, any further improvement was difficult, due to the difference in texture between its outer sphere and inner core. The results demonstrated that the roasting treatment led to a significant increase in the release of iron ions during the vanadium leaching process. The pre-removal of pyrite from the raw ore was necessary to reduce the concentration of iron ions in the leachate.
\end{abstract}

Keywords: vanadium; stone coal; impurity ions; acid leaching; pyrite

\section{Introduction}

Stone coal is a unique vanadium resource with a massive reserve in China, and the extraction of vanadium from stone coal has attracted attention for a long time. Muscovite is the primary vanadium-bearing mineral in stone coal because the $\mathrm{V}^{3+}$ substitutes the $\mathrm{Al}^{3+}$ from the dioctahedral structure as an isomorphism in muscovite [1,2]. Therefore, it is challenging to extract vanadium from stone coal.

Currently, blank roasting-acid leaching is an effective technique to recover vanadium from stone coal. Sulfuric acid is widely used as a leaching reagent, coupling with fluorides $\left(\mathrm{CaF}_{2}, \mathrm{HF}\right.$, and $\mathrm{NH}_{4} \mathrm{~F}$ ) to enhance the vanadium leaching efficiency [3,4]. However, the selectivity of vanadium is not as good as expected. Many impurity ions, especially iron ions, are inevitably leached along with the vanadium, which is detrimental to its subsequent purification and enrichment, and ultimately increases the cost of vanadium recovery [5]. Generally, the concentration of iron ions is 2.0-4.0 times higher than that of the vanadium ions in the leachate [6-8]. The separation of vanadium and iron ions has been one 
of the main concerns in the field of vanadium recovery from stone coal [9]. Many extraction reagents have been introduced to separate the vanadium and iron ions in the leachate [10,11]. In addition, novel leaching reagents and leaching technology, such as oxalic acid, have been used to reduce the iron leaching at its source, achieving a highly selective leaching of vanadium over iron [12]. However, their industrial application is unsatisfactory due to environmental and economic problems.

It is commonly believed that the iron ions in leachate come from pyrite or its roasted product. However, the process of pyrite combustion is complicated, and depends on combustion parameters such as temperature, particle size, flow condition and the atmosphere [13-15]. The phase transition behaviors of pyrite in coal combustion systems have been widely reported [16,17]. Hematite and magnetite are commonly believed to be the main roasting products, alongside some pyrrhotites and sulfates [18,19], which present significant differences in dissolution behaviors [20,21]. However, it is unclear what the roasted products of pyrite are, in the blank roasting treatment of vanadium-bearing stone coal, which is significantly different from the coal combustion system in combustion parameters. Furthermore, the dissolution behavior of pyrite and its roasted product under the vanadium leaching conditions are not particularly well analyzed. The aforementioned two combustion parameters are essential for evaluating and developing vanadium-iron separation technology in the extraction of vanadium from stone coal.

This work studied the correlation between the leaching behaviors of $\mathrm{V}$ and $\mathrm{Fe}$, from the mica-type vanadium-bearing stone coal in the acid leaching process. Both X-ray diffraction (XRD) and scanning electron microscopy (SEM) analyses were conducted to further analyze the phasal and structural transformations of pyrite after roasting and acid leaching treatment. This work further aimed to reveal the dissolution characteristics of pyrite in the extraction process of vanadium from stone coal. The results can provide useful guidance for the exploration of new technologies to be used in the source separation of vanadium over iron.

\section{Materials and Methods}

\subsection{Materials}

The raw ore of a mica-type stone coal was obtained from Hubei, China. The grades of $\mathrm{V}$ and Fe were $0.41 \%$ and $3.36 \%$, respectively. The main mineral phases were quartz, mica, calcite, feldspar and pyrite. The mica minerals contained approximately $90.0 \%$ of vanadium, and the pyrite contained approximately $90.0 \%$ of iron. The detailed results of chemical and phase analyses of the raw ore and its roasted products at $700{ }^{\circ} \mathrm{C}$ can be found in previous works [22]. The stone coal was ground to $-0.074 \mathrm{~mm}$ by a vibration mill.

The natural pyrite sample was collected from Hubei, China. The chemical analysis indicated that the major elements were Fe (45.65 wt.\%) and S (53.02 wt.\%), with a small amount of talc. The powder of pyrite was prepared by the dry hand-grinding of the pure crystals in an agate mortar with a diameter of less than $0.038 \mathrm{~mm}$. The data presented in this work were recorded with the same sample to avoid sample-dependent variation. All other reagents used in the experiments were of analytical grade.

\subsection{Roasting Treatment}

The roasting treatment was conducted in a muffle furnace (KRY-10, Yiheng, Shanghai, China) under air condition. The temperature of the muffle furnace was preset to $700^{\circ} \mathrm{C}$ before the mineral sample was settled. Following this, the mineral samples were roasted for $60 \mathrm{~min}$ at the preset temperature.

\subsection{Acid Leaching Experiments}

The sulfuric acid leaching experiments were carried out in a $250 \mathrm{~mL}$ flask for the stone coal sample, and in a $100 \mathrm{~mL}$ flask for the pure pyrite sample, with a temperature-controlled rotary platform at a rotating speed of $300 \mathrm{rpm}$. The influences of the sulfuric acid concentration, the leaching temperature, 
the leaching time and the solid to liquid ratio were all taken into consideration. The leaching solution and residue were also collected for the leaching efficiency calculation, phase and morphology analyses.

\subsection{X-ray Diffraction (XRD) Analysis}

The XRD analysis was conducted with a PANalytical Empyrean X-ray diffraction (PANalytical B.V., Almelo, The Netherlands) using $\mathrm{Cu} \mathrm{K} \alpha$ radiation.

\subsection{Microscopic Morphology Analysis}

The microscopic morphology observation was conducted by a JEOL JSM-IT300 scanning electron microscope (SEM, JEOL, Tokyo, Japan), equipped with a Bruker QUANTAX200-30 energy dispersive spectrometer (Bruker, Berlin, Germany).

\section{Results}

\subsection{The Correlation Between the Dissolution of V and Fe in the Blank Roasting-Sulfuric Acid Leaching Process}

The leaching efficiency of $\mathrm{V}$ and $\mathrm{Fe}$, from the raw stone coal and its roasted product at $700{ }^{\circ} \mathrm{C}$, were investigated under different $\mathrm{H}_{2} \mathrm{SO}_{4}$ concentrations, leaching temperature, leaching time and solid to liquid ratios. The experimental parameters are listed in Table 1, and the results are shown in Figures 1 and 2.

Table 1. The experimental parameters in the leaching of the raw ore and the roasted ore.

\begin{tabular}{ccccc}
\hline Groups & $\begin{array}{c}\mathbf{H}_{\mathbf{2}} \mathbf{S O}_{\mathbf{4}} \\
\text { Concentration } \\
(\mathbf{w t} \%)\end{array}$ & $\begin{array}{c}\text { Leaching } \\
\text { Temperature } \\
\left({ }^{\circ} \mathbf{C}\right)\end{array}$ & Leaching Time (h) & $\begin{array}{c}\text { Solid to Liquid } \\
\text { Ratio (g:mL) }\end{array}$ \\
\hline a & variable & 90 & 4 & $1: 2$ \\
b & 40 & variable & 4 & $1: 2$ \\
c & 40 & 90 & variable & $1: 2$ \\
d & 40 & 90 & 4 & variable \\
\hline
\end{tabular}
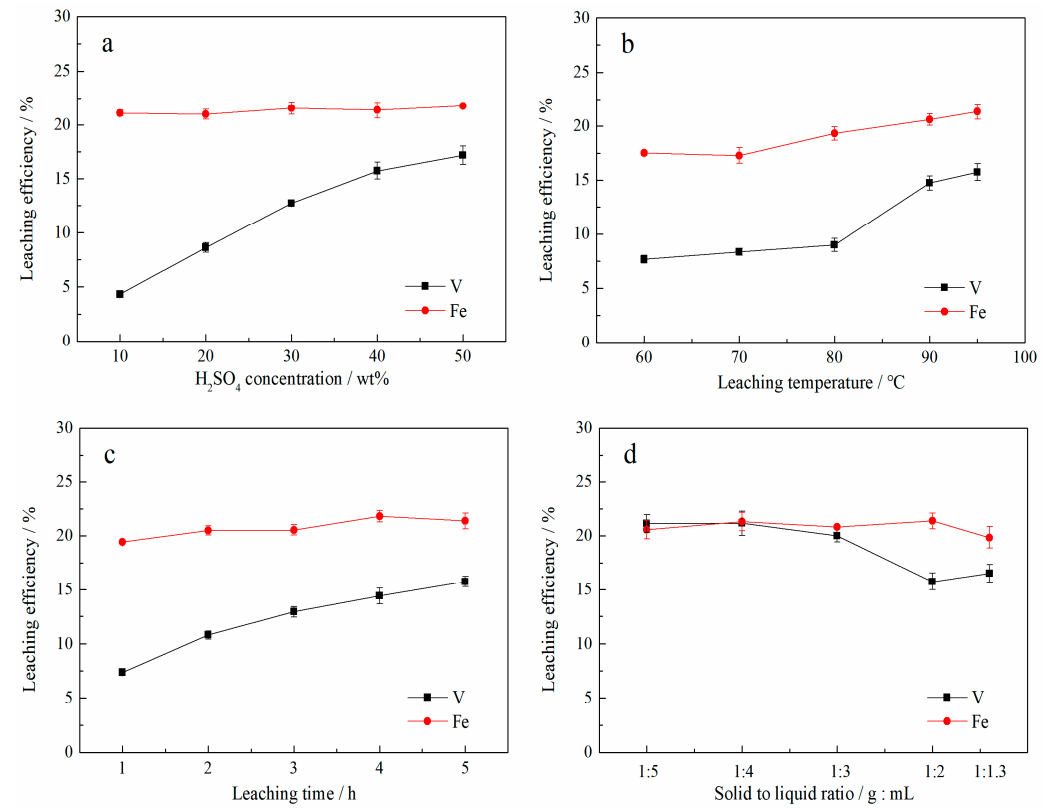

Figure 1. The leaching efficiency of $\mathrm{V}$ and Fe from the raw ore at different leaching conditions. Variables: (a) the $\mathrm{H}_{2} \mathrm{SO}_{4}$ concentration; (b) the leaching temperature; (c) the leaching time; (d) the solid to liquid ratio. 

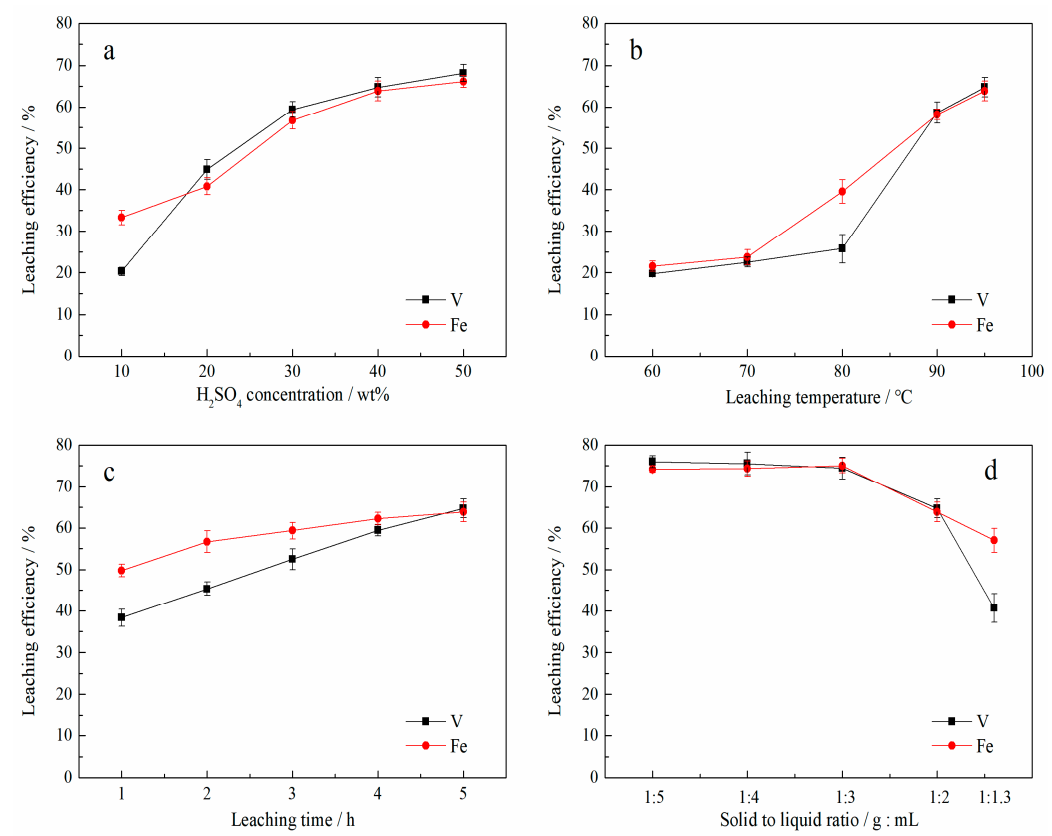

Figure 2. The leaching efficiency of $\mathrm{V}$ and Fe from the roasted ore at different leaching conditions. Variables: (a) the $\mathrm{H}_{2} \mathrm{SO}_{4}$ concentration; (b) the leaching temperature; (c) the leaching time; (d) the solid to liquid ratio.

The leaching efficiency of Fe in raw ore was approximately $20 \%$, under all of the experimental conditions (Figure 1). The variations of $\mathrm{H}_{2} \mathrm{SO}_{4}$ concentration, leaching temperature, leaching time and solid to liquid ratio did not have much of an affect. The highest leaching efficiency of Fe in raw ore was approximately $22 \%$. On the other hand, the leaching efficiency of $\mathrm{V}$ highly depended on the leaching parameters-especially the sulfuric concentration, leaching time and leaching temperature. The optimal leaching parameters for $\mathrm{V}$ extraction were: $\mathrm{H}_{2} \mathrm{SO}_{4}$ concentration at $50 \%$, leaching temperature at $95^{\circ} \mathrm{C}$, a leaching time of $5 \mathrm{~h}$ and a solid to liquid ratio of 1:4. However, the highest leaching efficiency of $\mathrm{V}$ was only $18 \%$ at its optimal condition. It has been demonstrated that the muscovite, which is the main vanadium-bearing mineral in stone coal, was resistant to attack by the hydrogen ions in the absence of fluoride [23]. In summary, the dissolution of Fe and V from the minerals in raw ore proved difficult, in line with previous reports [24]. Moreover, the releasing of Fe was faster than that of V.

For the roasted ore, the leaching efficiency of $\mathrm{Fe}$ and $\mathrm{V}$ both presented a positive correlation to the concentration of $\mathrm{H}_{2} \mathrm{SO}_{4}$ (Figure 2a), with a final leaching efficiency of $70 \%$ and $72 \%$, respectively. The leaching efficiency of Fe gradually increased from $20 \%$ to $70 \%$ (Figure 2b), with a rise in the leaching temperature from $60{ }^{\circ} \mathrm{C}$ to $95^{\circ} \mathrm{C}$. In regards to the leaching efficiency of $\mathrm{V}$, it was lower than $25 \%$ when the leaching temperature was lower than $80^{\circ} \mathrm{C}$, and saw a sharp increase from $25 \%$ to $60 \%$ when the leaching temperature increased from $80^{\circ} \mathrm{C}$ to $90^{\circ} \mathrm{C}$. The dissolution of $\mathrm{V}$ and Fe was also time-dependent (Figure 2c) - the leaching efficiency of Fe reached 50\% in $1 \mathrm{~h}$, and reached an equilibrium within $3 \mathrm{~h}$, with a final leaching efficiency of $62 \%$. In comparison, the leaching efficiency of $\mathrm{V}$ was at $37 \%$ in $1 \mathrm{~h}$, further increasing to $65 \%$ in the following $4 \mathrm{~h}$. As shown in Figure $2 \mathrm{~d}$, the leaching efficiency of Fe and V both decreased with an increase in the solid to liquid ratio. The optimal solid to liquid ratio for the leaching of vanadium from the roasted ore was 1:3.

The aforementioned leaching results indicated that the leaching efficiency of $\mathrm{V}$ and Fe from the roasted ore was much higher than that from the raw ore, and the release of Fe was faster than that of $\mathrm{V}$. The maximum leaching efficiency of $\mathrm{V}$ from stone coal was approximately $75 \%$ under its optimal leaching conditions, and the leaching efficiency of $\mathrm{Fe}$ was $73 \%$ under the same conditions.

Correlations among the leaching parameters of $\mathrm{H}_{2} \mathrm{SO}_{4}$ concentration, leaching temperature, leaching time, and solid to liquid ratio, alongside the leaching efficiency of $\mathrm{V}$ and $\mathrm{Fe}$, were analyzed by redundancy analysis (RDA) with Canoco software. These results are shown in Figure 3. 

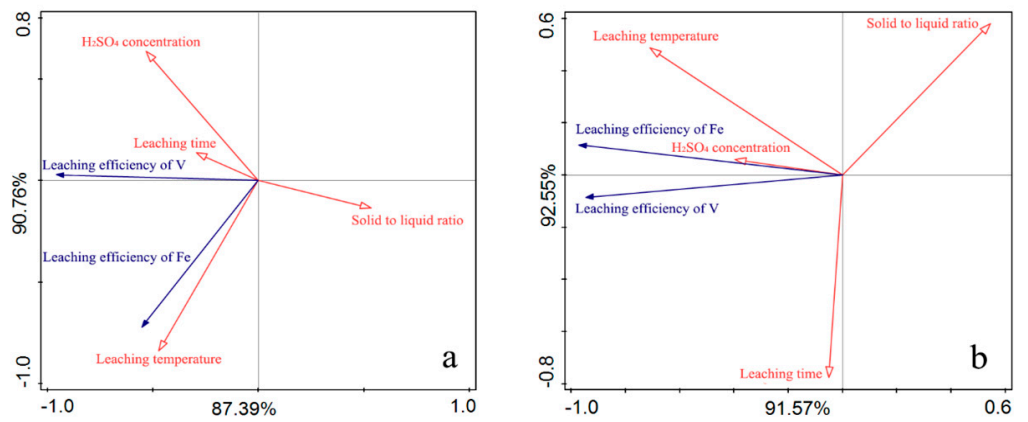

Figure 3. Redundancy analysis (RDA) of the leaching parameters and the leaching efficiency of $\mathrm{V}$ and Fe. (a) the raw ore; (b) the roasted ore.

For the raw ore (Figure 3a), the leaching efficiency of $\mathrm{V}$ presented a positive correlation to the leaching parameters of $\mathrm{H}_{2} \mathrm{SO}_{4}$ concentration, leaching temperature and leaching time, while presenting a negative correlation to the solid to liquid ratio. However, the leaching efficiency of Fe only showed a positive correlation to the leaching temperature, and its efficiency was, therefore, independent of the $\mathrm{H}_{2} \mathrm{SO}_{4}$ concentration, the leaching time and the solid to liquid ratio. The correlation between the leaching efficiency of $\mathrm{V}$ and Fe was insignificant. For the roasted ore (Figure 3b), the leaching efficiency of $\mathrm{V}$ and Fe presented a highly consistent trend. The leaching efficiency of $\mathrm{V}$ positively related to the $\mathrm{H}_{2} \mathrm{SO}_{4}$ concentration and the leaching temperature. Similarly, the leaching efficiency of Fe was positively related to the $\mathrm{H}_{2} \mathrm{SO}_{4}$ concentration, the leaching temperature and the leaching time. However, they both negatively related to the solid to liquid ratio. Interestingly, the correlation between the leaching efficiency of $\mathrm{V}$ and the leaching time, was insignificant compared with other parameters.

The acid leaching results indicated that the $\mathrm{V}$ in raw ore largely failed to be leached by direct acid leaching, but approximately $20 \%$ of Fe bearing mineral was dissolved. The leaching efficiency of $\mathrm{V}$ increased to $70 \%$ when the stone coal was roasted. Therefore, it can be concluded that the roasting treatment is a prerequisite for the efficient leaching of $\mathrm{V}$ from mica-type stone coal, as expected [25]. The $\mathrm{V}(\mathrm{III})$ in the stone coal is oxidized to $\mathrm{V}(\mathrm{IV})$ and $\mathrm{V}(\mathrm{V})$ in the blank roasting treatment, which was easily leached by the sulfuric acid [1]. However, the roasting treatment also significantly promoted the dissolution of the Fe bearing mineral, which will increase both the level of difficulty and the cost in subsequent purification and enrichment processes. The promotion of the release of iron ions can be attributed to the phase change of pyrite caused by the roasting treatment.

\subsection{The Dissolution Behavior of Pyrite and Its Roasted Product}

The influence of $\mathrm{H}_{2} \mathrm{SO}_{4}$ concentration, leaching temperature, leaching time and solid to liquid ratio on the dissolution of pyrite and its roasted product at $700^{\circ} \mathrm{C}$, were investigated. The detailed experimental parameters are listed in Table 2, and the results are shown in Figure 4.

Table 2. The experimental parameters in the leaching of the pyrite and its roasted product.

\begin{tabular}{ccccc}
\hline Groups & $\begin{array}{c}\mathbf{H}_{\mathbf{2}} \mathbf{S O}_{\mathbf{4}} \\
\text { Concentration (wt.\%) }\end{array}$ & $\begin{array}{c}\text { Leaching } \\
\text { Temperature }\left({ }^{\circ} \mathbf{C}\right)\end{array}$ & $\begin{array}{c}\text { Leaching } \\
\text { Time (h) }\end{array}$ & $\begin{array}{c}\text { Solid to Liquid } \\
\text { Ratio (g:mL) }\end{array}$ \\
\hline a & variable & 90 & 4 & $1: 40$ \\
b & 40 & variable & 4 & $1: 40$ \\
c & 40 & 90 & variable & $1: 40$ \\
d & 40 & 90 & 4 & variable \\
\hline
\end{tabular}



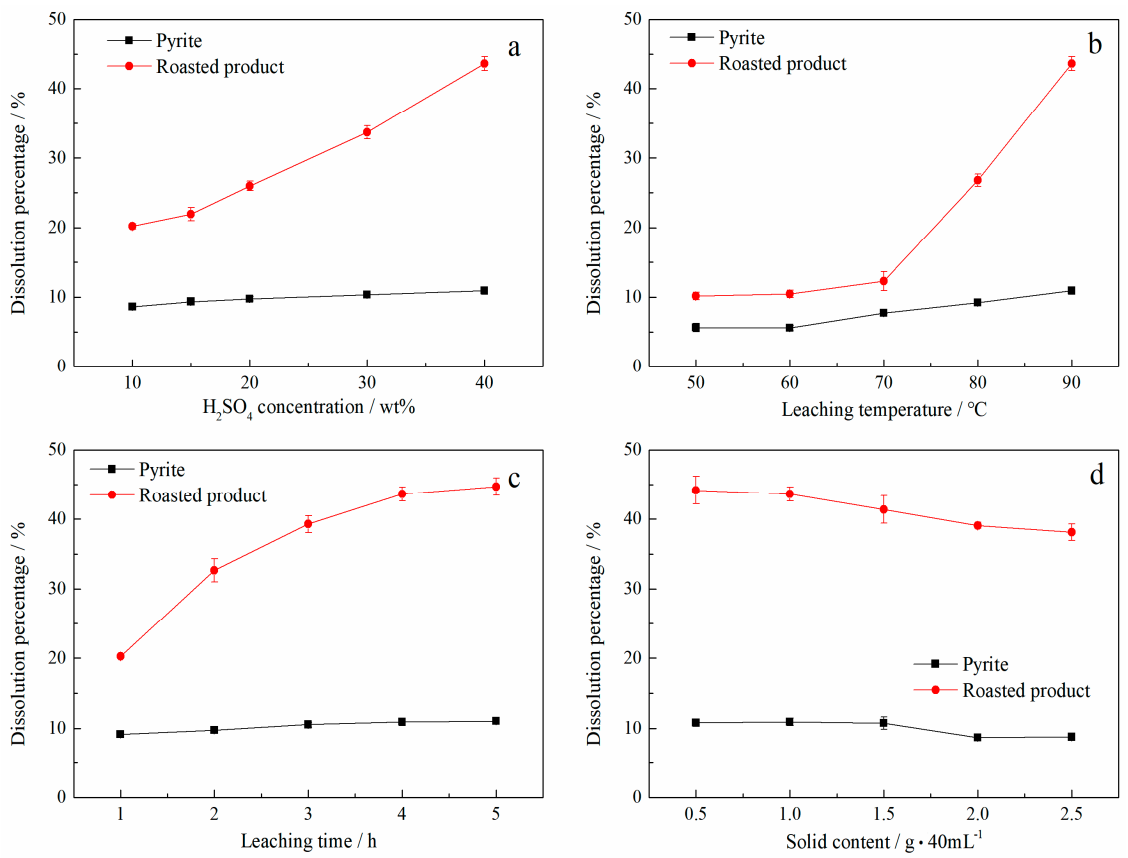

Figure 4. The dissolution of pyrite and its roasted product at different conditions. Variables: (a) the $\mathrm{H}_{2} \mathrm{SO}_{4}$ concentration; (b) the leaching temperature; (c) the leaching time; (d) the solid content.

As shown in Figure 4a, the highest dissolution percentage of the raw pyrite was only around $11 \%$, even when the $\mathrm{H}_{2} \mathrm{SO}_{4}$ concentration reached $40 \%$. By contrast, there was a clear linear dependence between the concentration of $\mathrm{H}_{2} \mathrm{SO}_{4}$, and the dissolution percentage of the roasted product of pyrite-approximately $20 \%$ with an $\mathrm{H}_{2} \mathrm{SO}_{4}$ concentration of $10 \%$, further increasing to $45 \%$ when the $\mathrm{H}_{2} \mathrm{SO}_{4}$ concentration increased to $40 \%$.

The dissolution percentage of the raw pyrite was less than $11 \%$, even at its highest leaching temperature of $90^{\circ} \mathrm{C}$ (Figure $4 \mathrm{~b}$ ). The leaching temperature significantly influenced the dissolution of the roasted product. The dissolution percentage increased from $11 \%$ to $45 \%$, with the leaching temperature elevated from $50{ }^{\circ} \mathrm{C}$ to $90^{\circ} \mathrm{C}$ after $4 \mathrm{~h}$ of leaching, in accordance with the leaching behavior of Fe in roasted stone coal. So, increasing the leaching temperature is proven to be beneficial to the dissolution of the roasted product of pyrite.

For the raw pyrite sample, the dissolution percentage increased from $9 \%$ to $11 \%$, with the leaching time increased from 1 to $5 \mathrm{~h}$-much lower than that of its roasted product (Figure 4c). The dissolution of the roasted product rapidly increased to $40 \%$ in the first $3 \mathrm{~h}$, and slowly increased to $46 \%$ in the last $2 \mathrm{~h}$. This means that the residual section in the roasted product was difficult to dissolve any further.

As shown in Figure $4 \mathrm{~d}$, the dissolution percentage of pyrite and its roasted product both slightly decreased with the increase of solid content. For the roasted product, when the solid content was $0.5 \mathrm{~g} / 40 \mathrm{~mL}$, the dissolution percentage of the sample was $44 \%$-approximately $7 \%$ higher than that of the group with a solid content of $2.5 \mathrm{~g} / 40 \mathrm{~mL}$. In regard to the iron ions, the concentration of iron ions in the leachate increased significantly with the increase in solid content. It could be deduced from the above results that the roasted product of pyrite was inadequately dissolved.

The leaching performance of pyrite and its roasted product showed that the dissolution of both pyrite and its roasted product had a positive correlation with the $\mathrm{H}_{2} \mathrm{SO}_{4}$ concentration, the leaching temperature and the leaching time, but had a negative correlation with the solid content. The raw pyrite was difficult to dissolve compared with its roasted product. In addition, the dissolution percentage of the roasted product was less than $45 \%$ in experimental conditions, and it proved difficult to improve further. This indicates that the dissolution of the roasted product of pyrite did not compare favorably with that of the pyrite cinder [20]. The phase and morphology analyses of the leaching 
residue of the roasted product were carried out by XRD and SEM to work out why the roasted product of pyrite could not be further dissolved.

\subsection{The Phase and Structure Transformations of Pyrite after Roasting and Acid Leaching Treatment}

The XRD patterns of the roasted pyrite and its leaching residue under different leaching times are shown in Figure 5.

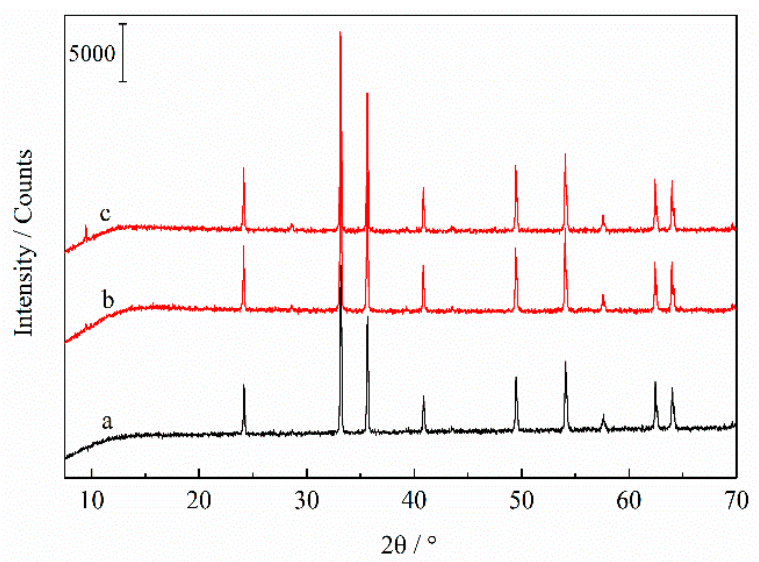

Figure 5. XRD patterns of the leaching residue of the roasted pyrite at different leaching times. (a) the roasted sample; (b) the leaching residue of the roasted sample with a leaching time of $1 \mathrm{~h}$;

(c) leaching residue of the roasted sample with a leaching time of $4 \mathrm{~h}$.

The hematite was the sole Fe-containing phase in the roasted product of pyrite at $700{ }^{\circ} \mathrm{C}$, in accordance with the theoretical results [19]. The phase of magnetite did not appear due to adequate oxygen in the roasting process. The main phase of its leaching residue was still hematite. While the hematite dissolved, the diffraction peak of the talc intensified with the increased leaching time. The XRD analysis indicates that there are no apparent changes in the components of the roasted product of pyrite before and after acid leaching. The microscopic morphology of the roasted product and its leaching residue under different leaching time was observed by SEM.

The SEM images indicated that the roasted product of pyrite was porous and stacked (Figure 6a). The increased porosity resulting from the decomposition of pyrite has been well documented [26]. The particles leached in sulfuric acid solution for $1 \mathrm{~h}$ (Figure $6 \mathrm{~b}$ ) presented higher roughness with many pits, and the roughness further increased with the leaching time (Figure 6c). However, local details showed that the particles leached for $4 \mathrm{~h}$ were dense and had a smooth surface. It can be concluded from the morphology variation and the leaching behavior that the outer sphere of the roasted product is porous and easily dissolved. However, the inner core of the roasted product is dense and difficult to be dissolved. A graphical representation (Figure 7) reveals the dissolution process of the roasted product, based on both the acid leaching results and the microscopic morphology analysis.
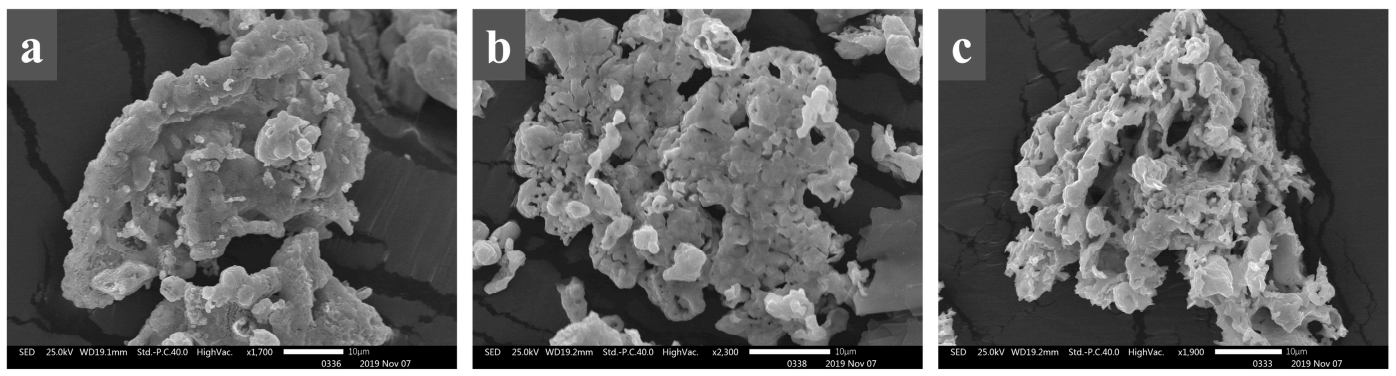

Figure 6. Microscopic morphology of the roasted product of pyrite and its leaching residue at different leaching times. (a) the roasted sample; (b) the leaching residue with a leaching time of $1 \mathrm{~h}$; (c) the leaching residue with a leaching time of $4 \mathrm{~h}$. 


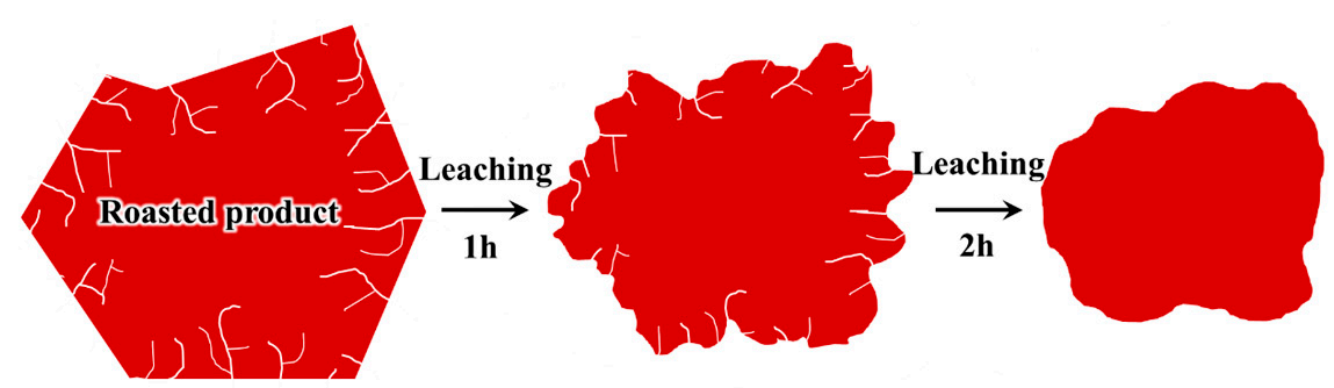

Figure 7. Graphical diagram for the dissolution process of the roasted product.

The pyrite particles after complete oxidation turn into hematite. The roasted product includes two different textures due to the complex reaction in the roasting process. The outer rim is porous, and the inner core is dense. The texture determines the dissolution behavior of the roasted product. The porous outer sphere dissolves much faster than the dense inner core. So, the dissolution percentage of the roasted product increases rapidly at the beginning of the leaching treatment, and then increases slowly with the extension of the leaching time.

\subsection{Implications for the Extraction of Vanadium from Stone Coal}

The roasting treatment is a prerequisite for the efficient leaching of $\mathrm{V}$ from the mica-type stone coal, as the $\mathrm{V}$ in raw ore was resistant to leaching by sulfuric acid. However, the roasting treatment also led to the pyrite's transformation into hematite, whose leaching behavior was similar to that of the vanadium-bearing minerals at their optimal leaching parameters. That is to say, the selective leaching of vanadium over iron, is impossible in the vanadium extraction process from stone coal by the blank roasting-sulfuric acid leaching method. Therefore, it is necessary to remove the pyrite from the raw ore prior to the roasting treatment, in order to reduce the concentration of iron ions in the leachate.

\section{Conclusions}

The leaching behaviors of $\mathrm{V}$ and Fe from stone coal both depended on the following leaching parameters: the concentration of sulfuric acid, the leaching temperature, the leaching time and the solid to liquid ratio. The leaching of $\mathrm{V}$ and Fe were significantly correlated. The roasted product of pyrite was hematite under the conditions in the blank roasting treatment of stone coal. The dissolution of the roasted product was much higher than that of the pyrite under the same leaching parameters. In conclusion, the roasting treatment led to a significant increase in the dissolution of iron in the blank roasting-acid leaching process of vanadium-bearing stone coal. Consequently, the pre-removal of pyrite from the raw ore before the roasting treatment is necessary to reduce the difficulty of the separation of $\mathrm{V}$ and $\mathrm{Fe}$ in the leachate.

Author Contributions: Conceptualization, X.W.; methodology, X.W., T.L. and Y.Y.; investigation, X.W.; resources, T.L. and Y.Y.; writing—original draft preparation, X.W.; supervision, Y.Z. and T.L.; project administration, Y.Z.; funding acquisition, X.W. and Y.Z. All authors have read and agreed to the published version of the manuscript.

Funding: This research was funded by the National Natural Science Foundation of China (51804225); the Hubei Provincial Natural Science Foundation of China (2018CFB122); the China Postdoctoral Science Foundation (2018M642934); and the Open Foundation of State Key Laboratory of Mineral Processing (BGRIMM-KJSKL-2019-13).

Conflicts of Interest: The authors declare no conflict of interest.

\section{References}

1. Zhang, Y.; Bao, S.; Liu, T.; Chen, T.; Huang, J. The technology of extracting vanadium from stone coal in china: History, current status and future prospects. Hydrometallurgy 2011, 109, 116-124. [CrossRef]

2. Wang, L.; Sun, W.; Zhang, Q. Recovery of vanadium and carbon from low-grade stone coal by flotation. Trans. Nonferrous Met. Soc. China 2015, 25, 3767-3773. [CrossRef] 
3. Zhu, Y.; Zhang, G.; Feng, Q.; Yiping, L.U.; Leming, O.U.; Huang, S. Acid leaching of vanadium from roasted residue of stone coal. Trans. Nonferrous Met. Soc. China 2010, 20, S107-S111. [CrossRef]

4. He, D.; Feng, Q.; Zhang, G.; Luo, W.; Ou, L. Study on leaching vanadium from roasted residue of stone coal. Min. Met. Explor. 2008, 25, 181-184. [CrossRef]

5. Chen, B.; Bao, S.; Zhang, Y.; Li, S. A high-efficiency and sustainable leaching process of vanadium from shale in sulfuric acid systems enhanced by ultrasound. Sep. Purif. Technol. 2020, 240, 116624. [CrossRef]

6. Li, X.; Wei, C.; Deng, Z.; Li, M.; Li, C.; Fan, G. Selective solvent extraction of vanadium over iron from a stone coal/black shale acid leach solution by d2ehpa/tbp. Hydrometallurgy 2011, 105, 359-363. [CrossRef]

7. Li, M.; Wei, C.; Fan, G.; Li, C.; Deng, Z.; Li, X. Extraction of vanadium from black shale using pressure acid leaching. Hydrometallurgy 2009, 98, 308-313. [CrossRef]

8. Ye, P.; Wang, X.; Wang, M.; Fan, Y.; Xiang, X. Recovery of vanadium from stone coal acid leaching solution by coprecipitation, alkaline roasting and water leaching. Hydrometallurgy 2012, 117, 108-115. [CrossRef]

9. Zhao, Y.; Chen, L.; Yi, H.; Zhang, Y.; Song, S.; Bao, S. Vanadium transitions during roasting-leaching process of vanadium extraction from stone coal. Minerals 2018, 8, 63. [CrossRef]

10. Li, X.; Deng, Z.; Wei, C.; Li, C.; Li, M.; Fan, G.; Huang, H. Solvent extraction of vanadium from a stone coal acidic leach solution using d2ehpa/tbp: Continuous testing. Hydrometallurgy 2015, 154, 40-46. [CrossRef]

11. Nguyen, T.H.; Lee, M.S. Solvent extraction of vanadium(v) from sulfate solutions using lix 63 and pc 88 a. J. Ind. Eng. Chem. 2015, 31, 118-123. [CrossRef]

12. Hu, P.; Zhang, Y.; Liu, T.; Huang, J.; Yuan, Y.; Zheng, Q. Highly selective separation of vanadium over iron from stone coal by oxalic acid leaching. J. Ind. Eng. Chem. 2017, 45, 241-247. [CrossRef]

13. Lopezarce, P.; Garciaguinea, J.; Garrido, F. Chemistry and phase evolution during roasting of toxic thallium-bearing pyrite. Chemosphere 2017, 181, 447-460. [CrossRef]

14. Jorgensen, F.R.A.; Moyle, F.J. Phases formed during the thermal analysis of pyrite in air. J. Therm. Anal. Calorim. 1982, 25, 473-485. [CrossRef]

15. Dunn, J.G.; De, G.C.; O'Connor, B.H. The effect of experimental variables on the mechanism of the oxidation of pyrite: Part 2. Oxidation of particles of size 90-125 $\mu \mathrm{m}$. Thermochim. Acta 1989, 155, 135-149. [CrossRef]

16. Zhou, Y.; Xu, P.; Cheng, H.; Liu, Q. Thermal phase transition of pyrite from coal. J. Therm. Anal. Calorim. 2018, 134, 2391-2396. [CrossRef]

17. Zhang, Y.; Li, Q.; Liu, X.; Xu, B.; Yang, Y.; Jiang, T. A thermodynamic analysis on the roasting of pyrite. Minerals 2019, 9, 220. [CrossRef]

18. Hu, G.; Damjohansen, K.; Wedel, S.; Hansen, J.P. Decomposition and oxidation of pyrite. Prog. Energy Combust. Sci. 2006, 32, 295-314. [CrossRef]

19. Srinivasachar, S.; Helble, J.J.; Boni, A.A. Mineral behavior during coal combustion 1. Pyrite transformations. Prog. Energy Combust. Sci. 1990, 16, 281-292. [CrossRef]

20. Wang, Y.; Xiao, L.; Liu, H.; Qian, P.; Ye, S.; Chen, Y. Acid leaching pretreatment on two-stage roasting pyrite cinder for gold extraction and co-precipitation of arsenic with iron. Hydrometallurgy 2018, 179, 192-197. [CrossRef]

21. Lee, S.O.; Tran, T.; Park, Y.Y.; Kim, S.J.; Kim, M.J. Study on the kinetics of iron oxide leaching by oxalic acid. Int. J. Miner. Process. 2006, 80, 144-152. [CrossRef]

22. Liu, X.; Zhang, Y.; Liu, T.; Cai, Z.; Sun, K. Pre-concentration of vanadium from stone coal by gravity using fine mineral spiral. Minerals 2016, 6, 82. [CrossRef]

23. Zheng, Q.; Zhang, Y.; Liu, T.; Huang, J.; Xue, N. Vanadium extraction from black shale: Enhanced leaching due to fluoride addition. Hydrometallurgy 2019, 187, 141-148. [CrossRef]

24. Wang, M.; Xiao, L.; Li, Q.; Wang, X.; Xiang, X. Leaching of vanadium from stone coal with sulfuric acid. Rare Met. 2009, 28, 1-4. [CrossRef]

25. He, D.; Feng, Q.; Zhang, G.; Ou, L.; Lu, Y. An environmentally-friendly technology of vanadium extraction from stone coal. Miner. Eng. 2007, 20, 1184-1186. [CrossRef]

26. Dunn, J.G.; De, G.C.; O'Connor, B.H. The effect of experimental variables on the mechanism of the oxidation of pyrite: Part 1. Oxidation of particles less than $45 \mu \mathrm{m}$ in size. Thermochim. Acta 1989, 145, 115-130. [CrossRef]

(C) 2020 by the authors. Licensee MDPI, Basel, Switzerland. This article is an open access article distributed under the terms and conditions of the Creative Commons Attribution (CC BY) license (http://creativecommons.org/licenses/by/4.0/). 